\title{
A ACESSIBILIDADE COMO INSTRUMENTO DE PARTICIPAÇÃO POLÍTICA E INCLUSÃO DIGITAL NA GOVERNANÇA ELETRÔNICA: uma análise dos portais do Poder Legislativo brasileiro.
}

\author{
Rosane Leal da Silva ${ }^{1}$ \\ Gislaine Ferreira Oliveira ${ }^{2}$
}

\section{RESUMO}

O presente artigo busca analisar como a acessibilidade digital potencializa a participação política e inclusão das pessoas com deficiência no processo democrático, no âmbito da Governança Eletrônica, a partir da observação dos canais de comunicação disponíveis. Para execução, utilizou-se o método de abordagem dedutivo, aliado ao método de procedimento monográfico e, as técnicas de pesquisa bibliográfica e observação direta, sistemática e nãoparticipativa dos portais do Poder Legislativo brasileiro. Deste modo, foi possível perceber que, embora os sites examinados disponibilizem canais de comunicação entre representantes e representados, ainda devem aprimorar os instrumentos de acessibilidade para efetiva navegação das pessoas com deficiência.

Palavras-chave: Acessibilidade; Governança Eletrônica; Inclusão digital; Participação política; Pessoas com deficiência.

\section{ACCESSIBILITY AS AN INSTRUMENT OF POLITICAL PARTICIPATION AND DIGITAL INCLUSION IN ELECTRONIC GOVERNANCE: an analysis of Brazil's Legislative Branch websites}

\begin{abstract}
This article aims to analyze how digital accessibility enhances the political participation and inclusion of people with disabilities in the democratic process, within the framework of Electronic Governance, from the observation of available communication channels. The method of deductive approach, combined with the method of monographic procedure, and the bibliographic research techniques and direct, systematic and non-participatory observation of Brazil's Legislative Branch websites were used for the article execution. Therefore, it was possible to perceive that, although the websites examined offer channels of communication between representatives and represented, they still need to improve accessibility tools towards effective navigation of people with disabilities.
\end{abstract}

Keywords: Accessibility; Electronic Governance; Digital inclusion; Political participation; Disabled people.

\section{INTRODUÇÃO}

\footnotetext{
${ }^{1}$ Doutora em Direito pela UFSC. Professora do Curso de Graduação e Mestrado em Direito da Universidade Federal de Santa Maria. Coordena o Núcleo de Direito Informacional (UFSM).

2 Mestre em Direito pelo Programa de Pós-Graduação em Direitos Emergentes na Sociedade Global, da Universidade Federal de Santa Maria. Integrante do Núcleo de Direito Informacional (NUDI). E-mail: gikoliveira@hotmail.com.
} 
As Tecnologias de Informação e Comunicação (TIC) possibilitaram o desenvolvimento da Governança Eletrônica e propiciaram a inserção do Estado na sociedade em rede. Percebe-se que o Poder Legislativo, assim como os outros Poderes, ao disponibilizar portais governamentais online, alterou significativamente a relação entre os representantes e os representados, permitiu um maior acesso a informações, a canais de transparência e novos meios de participação política.

Os mecanismos de acessibilidade são necessários para que todos os cidadãos possam ter acesso à Governança Eletrônica, uma vez que devem ter serviços e conteúdos ofertados a todos, sem exclusão. Como as pessoas com deficiência geralmente necessitam de algum auxílio para navegação, em vista da igualdade material, a acessibilidade contribui para autonomia e para o efetivo uso das vias de participação política ofertadas pelo Poder Legislativo Federal na sociedade em rede.

O presente trabalho tem como objetivo analisar como a acessibilidade digital potencializa a participação das pessoas com deficiência e a inclusão das mesmas no processo democrático no âmbito da Governança Eletrônica, a partir da observação dos canais de comunicação disponíveis no Poder Legislativo brasileiro. Para alcançar tal escopo, utilizou-se o método de abordagem dedutivo, uma vez que se parte das concepções gerais acerca da acessibilidade digital para pessoas com deficiência no contexto da Governança Eletrônica, para se chegar à análise dos portais, em clara lógica descendente, aliado ao método de procedimento monográfico.

Como técnicas de pesquisa, empregou-se a observação direta, sistemática e nãoparticipativa nos portais do Poder Legislativo Federal, especificamente as páginas da Câmara dos Deputados, do Senado Federal e do Congresso Nacional. A pesquisa foi realizada por meio de formulário estruturado na plataforma Google Drive, como instrumento de suporte, e desenvolvida no período entre novembro de 2015 a janeiro de 2016. Por fim, foi aplicada a técnica bibliográfica ao serem reunidos doutrinadores que abordam as temáticas desenvolvidas ao longo do trabalho.

$\mathrm{O}$ artigo foi dividido em duas partes. Na primeira, verificar-se-á importantes conceituações e seus entrelaçamentos, referente à inserção do Poder Legislativo na sociedade em rede e as novas possibilidades da participação política, com ênfase nos instrumentos de acessibilidade para as pessoas com deficiência e sua inclusão digital. Já no segundo capítulo, 
apresentar-se-á a análise dos portais do Poder Legislativo brasileiro no que concerne à acessibilidade dos canais de participação política e inclusão das pessoas com deficiência.

\title{
1 A PARTICIPAÇÃO POLÍTICA DAS PESSOAS COM DEFICIÊNCIA NA
}

GOVERNANÇA ELETRÔNICA: a acessibilidade como instrumento de inclusão e igualdade.

O desenvolvimento das Tecnologias de Informação e Comunicação (TIC) transformaram de forma significativa diversos setores da sociedade. Também propiciaram o surgimento da Governança Eletrônica que representa a inserção do Estado na sociedade em rede. De acordo com José Maria Jardim (2004, p. 6-7):

\begin{abstract}
O termo e-governance (governança eletrônica) centra-se em uma visão ampla de governabilidade, sinalizando como opera, trabalha e se organiza a sociedade à qual o governo deve assegurar o acesso e a participação em diversas redes de informação. Possui um sentido mais amplo e abarca o conceito de e-government, o qual teria como foco as tarefas gerenciais que conduzem à interação cidadania-governo. Do ponto de vista estritamente tecnológico, o E-gov visaria o cidadão como um ponto a conectar dentro de uma rede, enquanto a governabilidade eletrônica asseguraria o acesso e participação dos cidadãos individual e coletivamente dentro das redes governamentais
\end{abstract}

Nesse sentido, a Governança Eletrônica propicia a presença da web, a interação, a transação, a transformação e, por fim, a e-democracia (SIAU; LONG, 2005, p. 446). Sendo a democracia eletrônica aquela que ocasiona forte impacto, uma vez que "[...] es visto como una nueva forma de participación ciudadana que puede ayudar a contrarrestar la bien conocida apatía electoral y otras formas de participación en los avatares de la vida socio-económica y política [...]” (ZAMBRANO, 2010, p. 20).

O Brasil está na $37^{a}$ posição, integrando o top 50 em e-participação mundial, conforme aponta o Relatório da Organização das Nações Unidas (ONU) denominado "United Nations E-Government Survey 2016: E-government in support of sustainable development" (2016, p. 56). Ao comparar os atuais resultados com o documento de 2014 (ORGANIZAÇÕES..., 2014, p. 66), nota-se que na pesquisa lançada em 2016, o país avançou da pontuação de "meio alto" para "alto" referente ao índice que engloba os três estágios que e-participação, os quais são: a informação online, a e-consulta e a participação em decisões virtuais. 
Especificamente nas duas últimas etapas referidas, outro documento da Organização das Nações Unidas, o "World Public Sector Report 2003: E-government at the Crossroads" (2013, p. 19), explica que a e-consulta possibilita a criação de canais de comunicação, uma vez que o governo incentiva a participação dos cidadãos. Enquanto que a participação nas decisões públicas por meio virtual, acontecem quando o governo cria vias de interação e debate, além de apresentar feedback acerca do resultado dos assuntos abordados.

Essas transformações geradas pelo emprego das Tecnologias de Informação e Comunicação (TIC) ainda proporcionam novas formas de acesso à informação e uma evidente alteração na relação entre o Poder Público e a sociedade, conforme destaca Diéguez e Ríos (2012, p. 247), “a través de la utilización intensiva de las TIC por parte de la administración gubernamental, el territorio ya no constituye un elemento limitante para la socialización y la interacción entre gobierno y ciudadanos". Os portais online hospedam-se na internet e estão disponíveis para acesso vinte e quatro horas por dia, em um modelo designado de One-Stop Government, que amplia oportunidades, ao contrário das instituições físicas que funcionam em horário comercial e dependem, diretamente, dos servidores públicos.

De acordo com Dufloth, Freitas e Rocha (2014, p. 40), este modelo remete à “integração dos serviços públicos a partir da perspectiva dos usuários dos serviços públicos (cidadãos, empresas, etc.), de modo a permitir o acesso ininterrupto aos serviços públicos”. Assim, para que seja viável, é indispensável integrar as atividades dos órgãos governamentais em um único local (físico ou eletrônico), possibilitando a obtenção de informações e serviços do Poder Público.

No entanto, há o problema do desacordo entre a demanda de informações e o retorno do Estado, por mais que o canal de comunicação seja ininterrupto através da internet, o responsável pelas respostas às demandas não é uma máquina e possui limitações de tempo e capacidade. Então, pode-se afirmar que "no caso brasileiro, muito ainda tem de ser feito para se aproximar da situação ideal no que se refere à proposta de governo eletrônico no modelo de One-Stop Government” (DUFLOTH; FREITAS; ROCHA, 2013, p. 40).

No caso do Poder Legislativo brasileiro, sua inserção na sociedade em rede, através de sites oficiais, gerou profundas alterações no processo democrático. Bernardos, Santos e Rover (2013, p. 286) dispõem que o uso da internet é essencial para aperfeiçoar o sistema democrático, tanto na modernização das administrações, quanto na aproximação entre 
representantes e representados, com o intuito de promover a abertura dos governos tradicionais para um modelo que opere sob a lógica de redes.

No mesmo sentido ressalta Manuel Castells (2011, p. 368), que “[...] causa um impacto não só nas eleições, mas na organização política, processos decisórios e métodos de governo, em última análise, alterando a natureza da relação entre Estado e sociedade [...]". Essa proximidade entre representantes e representados através da Governança Eletrônica deve ser oportunizada a todos os cidadãos, por isso é essencial implementar projetos e políticas públicas, principalmente referentes à universalização do acesso às tecnologias para aqueles que são excluídos digitalmente e criar formas efetivas de acesso à informação e participação política.

Em vista disso, o Poder Público, em destaque o Legislativo, deve ter uma atenção especial em relação às particularidades econômicas, sociais e culturais dos cidadãos, as quais são primordiais para desenvolver medidas de inclusão e participação política da sociedade, e estas precisam ser implementadas também na sociedade em rede (LEAL, 2006, p. 65). Ao mesmo tempo, reforçam Braga, Alves, Figueiredo e Santos (2008, p. 13) que "a contribuição da votação eletrônica para o reforço da governança do setor público dá-se pela solidificação da democracia, da cidadania, da igualdade, da voz e da representação; de forma complementar, pelos ganhos de eficiência e transparência em todo o processo".

Ao oportunizar a todos o acesso e participação política online pratica-se um dos princípios da Governança Eletrônica, o qual aduz, sem exceção, que todos devem navegar pelos sites, em igualdade de condições. Desta forma, são imprescindíveis o desenvolvimento de políticas de acessibilidade nos portais governamentais, que se fundamentam no direito humano e fundamental do cidadão em acessar informações públicas, de modo que seja possível questionar, fiscalizar, reivindicar e influenciar as decisões dos seus representantes políticos, com postura crítica, em pleno exercício de sua cidadania.

Logo, para a universalização do acesso das páginas governamentais, efetivação de serviços online e participação política é necessário que sejam observadas as particularidades de seus usuários, sendo importante a disponibilização de mecanismo que facilitem e auxiliem a navegação, contemplando, assim, a acessibilidade nos sites. As políticas de acessibilidade nos sites governamentais oportunizam a participação, pois "a cidadania na sociedade em rede depende também do domínio dos instrumentos que nos permitem lidar com a mídia como 
mais uma linguagem natural, o desenvolvimento de uma habilidade além da sua definição mais tradicional" (CARDOSO, 2007, p. 313).

Ressalta-se como o avanço tecnológico contribuiu para a independência das pessoas com deficiência, uma vez que o computador e acesso à internet cooperaram para a inclusão. Enquanto que antes enfrentavam diversas dificuldades de locomoção e atendimento, agora com alguns cliques é possível que usufruam de diversos direitos, como a possibilidade de estudar, trabalhar, participar de decisões políticas, além de se comunicar com outras pessoas em qualquer lugar do mundo.

Portanto, para uma experiência positiva nos sites e portais do governo e desenvolvimento desse novo modelo democrático, que envolve a representação aliada à participação cidadã, no momento do acesso dos usuários para consultas a informações ou utilização de serviços, as páginas devem ser acessíveis a todos. Também, devem estar em consonância com as recomendações e padronizações exaradas, e implementadas as ferramentas que facilitem a navegação.

Em consonância, Álvaro Sanchez Bravo (2010, p. 31) defende a necessidade de serem considerados os contextos global e local como forma de promover a inclusão das pessoas com deficiência na sociedade em rede. Além disso, os mecanismos de acessibilidade devem ser desenvolvidos diretamente para suas necessidades, de maneira que elas possam usufruir dos benefícios que as TIC podem lhe oferecer.

Nesse sentido, conceitua-se acessibilidade, em perspectiva ampla, como uma condição ou instrumento que melhora a qualidade de vida das pessoas e deve estar presente tanto nos meios físicos, nos técnicos, nos dispositivos existentes e no mundo virtual (HAZARD; GALVÃO FILHO; REZENDE, 2007, p. 20). Assim, quando se refere às pessoas com deficiência, o fenômeno de exclusão exige políticas públicas do governo para a inclusão digital e aplicação de instrumentos de acessibilidade para que possam participar das decisões públicas.

Destaca-se que a acessibilidade se dirige a todos, mas beneficia especialmente as pessoas com deficiência. A partir da conceituação legal de deficiência, possível a partir do exame dos Decretos no 5.296 de 2004 e n 3.298 de 1999, compreende-se que pode ser tanto física, como auditiva, visual, mental ou múltipla. Sendo que a deficiência física envolve uma modificação total ou parcial de uma ou mais partes do corpo humano, com o comprometimento da função física (BRASIL, 2004) e pode apresentar-se nas mais diversas 
formas, como: "paraplegia, paraparesia, monoplegia, monoparesia, tetraplegia, tetraparesia, triplegia, triparesia, hemiplegia, hemiparesia, ostomia, amputação ou ausência de membro, paralisia cerebral, nanismo, membros com deformidade congênita ou adquirida [...]" (BRASIL, 1999).

São essas pessoas com deficiência atendidas pelos mecanismos de acessibilidade e sua efetivação contempla um avanço, principalmente na sociedade em rede. Para compreender como a acessibilidade digital potencializa a participação política das pessoas com deficiência é necessário entender a mudança de concepção de pessoa com deficiência, que passou de um modelo biomédico para o modelo social, adotado na Convenção Internacional de Direitos das Pessoas com Deficiência (ORGANIZAÇÃO..., 2006).

A idealização de modelo biomédico da deficiência considerou, por muito tempo, a deficiência como uma enfermidade, atentando-se somente ao critério patológico, ao passo que compreendia que um corpo com impedimentos deveria ser objeto de intervenção dos saberes científicos. Referidas barreiras eram classificadas, restritamente, pela ordem médica, a qual descrevia as lesões e as doenças como desvantagens naturais e indesejadas (DINIZ; BARBOSA; SANTOS, 2010, p. 68). Práticas de reabilitação ou curativas eram oferecidas e até mesmo impostas aos corpos, com o intuito de reverter ou atenuar os sinais da anormalidade.

Nas palavras de Diniz, Barbosa e Santos (2010, p. 67) "os impedimentos corporais eram classificados como indesejáveis e não simplesmente como uma expressão neutra da diversidade humana, tal como se deve entender a diversidade racial, geracional ou de gênero". Por isso, o corpo com obstáculos, na perspectiva do modelo biomédico, deveria se submeter à metamorfose para a normalidade, seja pela reabilitação, pela genética ou por práticas educacionais.

Diversamente do entendimento do modelo biomédico, com o avanço para o modelo social visualiza-se que não era a natureza quem oprimia, mas a cultura da normalidade, que descrevia alguns corpos como indesejáveis (DINIZ; BARBOSA; SANTOS, 2010, p. 69). Com o modelo social, a deficiência passou a ser compreendida não só como como um estado patológico - como era considerada pelo modelo biomédico - mas como uma manifestação da diversidade humana. Uma vez que,

consoante esse modelo, a deficiência advém do resultado da relação entre um corpo com impedimentos e a sociedade, ou seja, é avaliada com base na participação de uma pessoa com impedimentos corporais na vida. O corpo com impedimentos não é 
mais a medida solitária para a definição de deficiência, pois tão decisivo quanto os impedimentos corporais é o ambiente que impõe restrições e barreiras à plena participação (BARBOSA; DINIZ; SANTOS, 2010, p. 46).

Nessa senda, empreende-se que o modelo social entende que são as barreiras sociais que, ao ignorar os corpos com impedimentos, provocam a experiência da desigualdade. Foi nesse contexto que a necessidade de estabelecer políticas públicas passou a refletir as ideias de inclusão social e eliminação de obstáculos à participação e inclusão, reconhecendo a pessoa com deficiência como um sujeito de direito, com autonomia e vontades.

Assim, entender a acessibilidade como instrumento de reduzir qualquer limitação imposta às pessoas com deficiência está em consonância com o que a Convenção sobre os Direitos das Pessoas com Deficiência (ORGANIZAÇÃO..., 2006). Deve-se defender a acessibilidade como um mecanismo para que as pessoas possam viver com dignidade e autonomia, tanto fornecendo o ingresso nos espaços físicos, quanto garantindo acesso a informações e participação política online através das tecnologias de informação e comunicação (ORGANIZAÇÃO..., 2006).

Também, a Convenção sobre os Direitos das Pessoas com Deficiência em diversos momentos inclui em seu texto o princípio da igualdade. Destaca-se o artigo $1^{\circ}$ em que assume como propósito promover, "proteger e assegurar o exercício pleno e equitativo de todos os direitos humanos e liberdades fundamentais por todas as pessoas com deficiência e promover o respeito pela sua dignidade inerente" (ORGANIZAÇÃO..., 2006) e a participação das pessoas com deficiência na sociedade em igualdade de condições com os demais. Ainda, reconhece no artigo $3^{\circ}$ (ORGANIZAÇÃO..., 2006), alínea "e", a igualdade de oportunidades como princípio geral.

A igualdade material concretiza-se na máxima em que se deve trata-se "[...] por 'igual o que é igual e desigualmente o que é desigual'. Diferentemente da estrutura lógica formal de identidade, a igualdade pressupõe diferenciações. A igualdade designa uma relação entre diversas pessoas e coisas [...]" (CANOTILHO, 2003, p. 428). As pessoas com deficiências necessitam de políticas públicas que efetivem a igualdade material, sendo insuficiente a concretização da igualdade formal.

Em conformidade com a Convenção sobre os Direitos das Pessoas com Deficiência, a Lei Brasileira de Inclusão da Pessoa com Deficiência dispõe em seu artigo $4^{\circ}$ (BRASIL, 2015) que "toda pessoa com deficiência tem direito à igualdade de oportunidades com as demais pessoas e não sofrerá nenhuma espécie de discriminação". Sendo que o princípio da 
igualdade de oportunidades apresentado tem como objetivo, de acordo com Norberto Bobbio (1997, p. 160-161) " “...] colocar todos os membros daquela determinada sociedade na condição de participar da competição pela vida, ou pela conquista do que é vitalmente mais significativo, a partir de posições iguais [...]".

De acordo com Pérez Luño (2007, p. 38), “[...] la distinción entre igualdad formal e igualdade material, más que una alternativa implica un proceso de ampliación del principio de igualdad en las sociedades pluralistas y democráticas". A igualdade material contribui para a mudança de paradigma, como já apresentado passou a compreender a deficiência através do modelo social e não do modelo biomédico. Essa evolução é gradativa, exige uma efetiva mudança da sociedade e, de como o Estado legisla e executa políticas públicas para a proteção dos direitos das pessoas com deficiência.

Nesse contexto, para atender as pessoas com deficiência que se viabiliza a acessibilidade nos portais da Governança Eletrônica. Sendo que a inacessibilidade dos sites governamentais brasileiros contribui para o aprofundamento da exclusão digital, uma vez que afasta a participação de aproximadamente $23,9 \%$ da população brasileira, que declararam ter pelo menos um tipo de deficiência, conforme aponta os resultados do Censo Demográfico 2010 do IBGE (BRASIL, 2010, p. 73).

Visualiza-se como a acessibilidade contribui para a inclusão das pessoas com deficiência e como as TIC permitem uma maior participação política, mas para que seja possível a atuação de todos os cidadãos, esses mecanismos devem ser empregados nos portais governamentais. A inserção do Poder Legislativo brasileiro na sociedade em rede é considerada um avanço de aproximação entre os representantes e os representados, por isso é fundamental verificar os se os canais de comunicação online disponibilizados apresentam os instrumentos de acessibilidade para que as pessoas com deficiência possam exercer sua cidadania ativamente, análise exposta no próximo capítulo.

\section{O ESTADO DA ARTE DA ACESSIBILIDADE NOS PORTAIS DO PODER} LEGISLATIVO BRASILEIRO: uma análise das oportunidades de participação política através dos meios de comunicação e inclusão digital das pessoas com deficiência.

No presente capítulo apresentar-se-á o panorama da acessibilidade destinado às pessoas com deficiência, nos canais de comunicação e participação política disponibilizados 
nos portais do Poder Legislativo brasileiro, constituído pelos sites da Câmara dos Deputados (BRASIL, 2016a), do Senado Federal (BRASIL, 2016b) e do Congresso Nacional (BRASIL, 2016c). A observação estruturou-se através de um formulário na plataforma do Google Docs, como instrumento de suporte, e cada portal foi avaliado duas vezes, no período de novembro de 2015 até janeiro de 2016, de acordo com o procedimento aplicado por Santos, Bernardes e Rover (2012, p. 61-66).

Os sítios eleitos para aplicar a técnica de pesquisa de observação direta, sistemática e não participativa foram do Poder Legislativo Federal brasileiro, uma vez que os parlamentares são representantes do povo, em especial a Câmara de Deputados. O exercício do poder político, pertencente à população, pelo referido Poder é garantido pelo artigo $1^{\circ}$ da Carta Magna (BRASIL. 1988), o que justificaria (e até mesmo exigiria) que disponibilizassem um site acessível a todos e com canais para comunicação e participação política, acesso a informações públicas e serviços.

Assim, o presente artigo passa à exposição dos resultados da observação realizada nos referidos sites, com foco nas possibilidades de participação política a partir da verificação da disponibilização de canais de comunicação. Isto é, essa análise realizada teve como escopo perceber em que medida há canais de comunicação entre os representantes e representados, com possibilidade para participação política e exercício da cidadania e, na hipótese de existência, se esses meios de comunicação atentam para os mecanismos de acessibilidade.

A internet ampliou as formas de participação política da população e conforme Wilson Gomes (2011, p. 27) acertadamente aponta, o avanço de uma democracia digital através do emprego de dispositivos tecnológicos tem como finalidade colaborar, reforçar ou corrigir aspectos das práticas políticas e sociais do Estado e dos cidadãos. A partir dos portais online da Governança Eletrônica percebe-se que a sociedade em rede aumentou os “[...] instrumentos e oportunidades de participação do cidadão nas esferas de decisões sobre políticas públicas (...), incrementando o pluralismo, da representação das minorias e da consolidação dos direitos dos indivíduos e dos grupos socialmente vulneráveis" (GOMES, 2011, p. 28).

Nesse contexto revela-se necessário verificar quais os meios para interação ofertados pelos portais do Poder Legislativo Federal à população. A observação empreendida permitiu verificar que tanto o portal do Senado Federal quanto o da Câmara de Deputados informam o endereço físico e telefone para contato, sendo que há o número de telefone gratuito (0800). 
Porém, nenhum dos dois sites esclarece o horário de atendimento e funcionamento ao público ${ }^{3}$.

Quanto ao quesito da publicação de e-mail do órgão para a prestação de informações somente o Senado Federal o disponibilizou na seção "Fale com o Senado", juntamente com as opções de telefone 0800, endereço para envio de correspondência, formulário, e-mail para atendimento ao usuário do processo legislativo e para assessoria de imprensa. A presença de e-mail, de acordo com a TIC Governo Eletrônico 2015 (BRASIL, 2016d, p. 165) “[...] a maior parte dos órgãos federais que possuem website ofereceram pelo menos o endereço de e-mail para contato com os cidadãos $(98 \%)$ [...]”.

Enquanto percebe-se a utilização do e-mail em quase totalidade das instituições, a Câmara dos Deputados é adepta de formulário como canal de comunicação padrão entre representantes e representados, denominado "Fale Conosco", somado às informações de telefone e endereço físico, não apresentando um e-mail de contato especifico. A referida pesquisa também ressalta que,

Fale conosco e formulários eletrônicos foram as formas de comunicação mais ofertadas depois do e-mail: nos órgãos federais, $94 \%$ e $90 \%$, respectivamente. (...) O atendimento on-line em tempo real foi a forma de comunicação com os cidadãos menos citada entre os órgãos públicos, disponibilizados nos websites de apenas $11 \%$ dos órgãos federais [...]. (BRASIL, 2016d, p. 165).

Além do contato institucional, é importante assegurar que os cidadãos tenham a oportunidade de contatar diretamente aquele parlamentar em quem votou nas eleições, com ênfase na ideia de que "la ciudadanía democrática no se agota en el compromisso electoral. Es participar en la creación de políticas que atiendan las necesidades de los seres humanos y contextualicen sus problemas" (MARTÍNEZ; PRIETO, 2007, p. 334). Nesse âmbito, constatou-se que o portal do Senado Federal, no setor de transparência, possui na ferramenta "Fale com os Senadores" um arquivo em pdf, com as seguintes informações: nome parlamentar, partido, UF, titularidade, mandato, telefones, fax, e-mail, chefe de gabinete e endereço.

Já no portal da Câmara dos Deputados há a opção de formulário "Fale com o Deputado”, onde não há a divulgação do e-mail, o que oportuniza a comunicação direta com o deputado de interesse. Acima do formulário há advertências acerca do não encaminhamento de mensagens com palavras de baixo calão direcionadas aos parlamentares, além do que

\footnotetext{
${ }^{3}$ Somente o Congresso Nacional destaca o horário de funcionamento, mas é para fins turísticos.
} 
eventuais informações institucionais podem ser respondidas previamente por órgãos da Casa, medidas que podem ser adotadas em conjunto com o envio da mensagem para o parlamentar selecionado.

O mais inusitado é que para o envio da demanda é necessário o preenchimento de uma enquete denominada "A Câmara deseja conhecer você", que solicita informações como sexo, faixa etária, UF e cidade. Tal imposição causa surpresa, especialmente porque exige dados pessoais do cidadão, quando a Lei de Acesso à Informação nº 12.527 (BRASIL, 2011), em seu artigo 10, parágrafo $1^{\circ}$, dispensa alguns desses requisitos e determina que "a identificação do requerente não pode conter exigências que inviabilizem a solicitação".

A justificativa presente no sítio, conforme se pode observar a seguir, é que essas informações servem para formação de estatísticas do órgão, assegurando o sigilo dos dados. Essa afirmação carece, no entanto, de maiores garantias, especialmente porque o Brasil não ainda não possui Lei de Proteção de Dados Pessoais.

Figura 1 - Formulário Fale com o Deputado: a Câmara deseja conhecer você

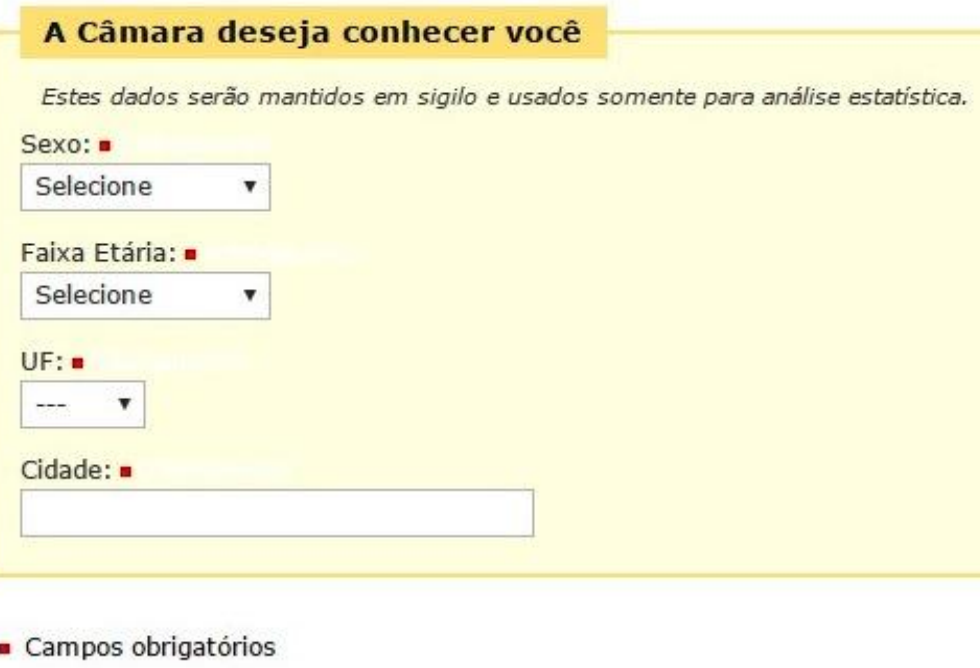

(BRASIL, 2016a)

Quanto à acessibilidade dos formulários, ambos os sites pesquisados apresentam campos de preenchimento acessíveis por meio das teclas ou cursor, com destaque para campos de preenchimento obrigatório. Ainda, referente aos formulários disponíveis, quanto à identificação do requerente e a especificação da informação solicitada constata-se que no 


\section{A acessibilidade como instrumento de participação política e inclusão digital na governança eletrônica: Uma análise dos portais do poder legislativo brasileiro}

Senado Federal ${ }^{4}$ exige a identificação do requerente, mas se for incompleta será considerado mensagem anônima. Este site também não exige que se identifique o tipo de mensagem.

Fernando Galindo Ayuda (2012, p. 46), com acerto afirma que para o exercício de acesso à informação requer uma inequívoca identificação do demandante, para o Poder Público possa enviar uma resposta. No mesmo sentido Carvacho T. (2010, p. 59) aduz que "[...] el anonimato y el uso de nicknames impidem la generación de una comunicación real: asegura la información, no necessariamente la comunicación [...]”, isto é, o demandante irá conseguir pedir a informação, mas não obterá respostas, não consolidando a comunicação.

Um quesito positivo no formulário do Senado Federal é a pluralidade de canais para resposta, que o demandante pode escolher entre e-mail ou carta postal, atentando-se para os índices de exclusão digital brasileira. Mas também exige informações sem relação com a demanda, para fins estatísticos como: UF, sexo, faixa etária, escolaridade e reconhece o IP do computador que é enviado a solicitação, já criticados nos parágrafos anteriores. Além de todas essas exigências, ainda solicita o consentimento para a divulgação da mensagem nas mídias do Senado Federal e possibilita o anexo de um arquivo, como a Figura 2 a seguir ilustra.

Figura 2 - Formulário Fale com o Senado: sobre você.

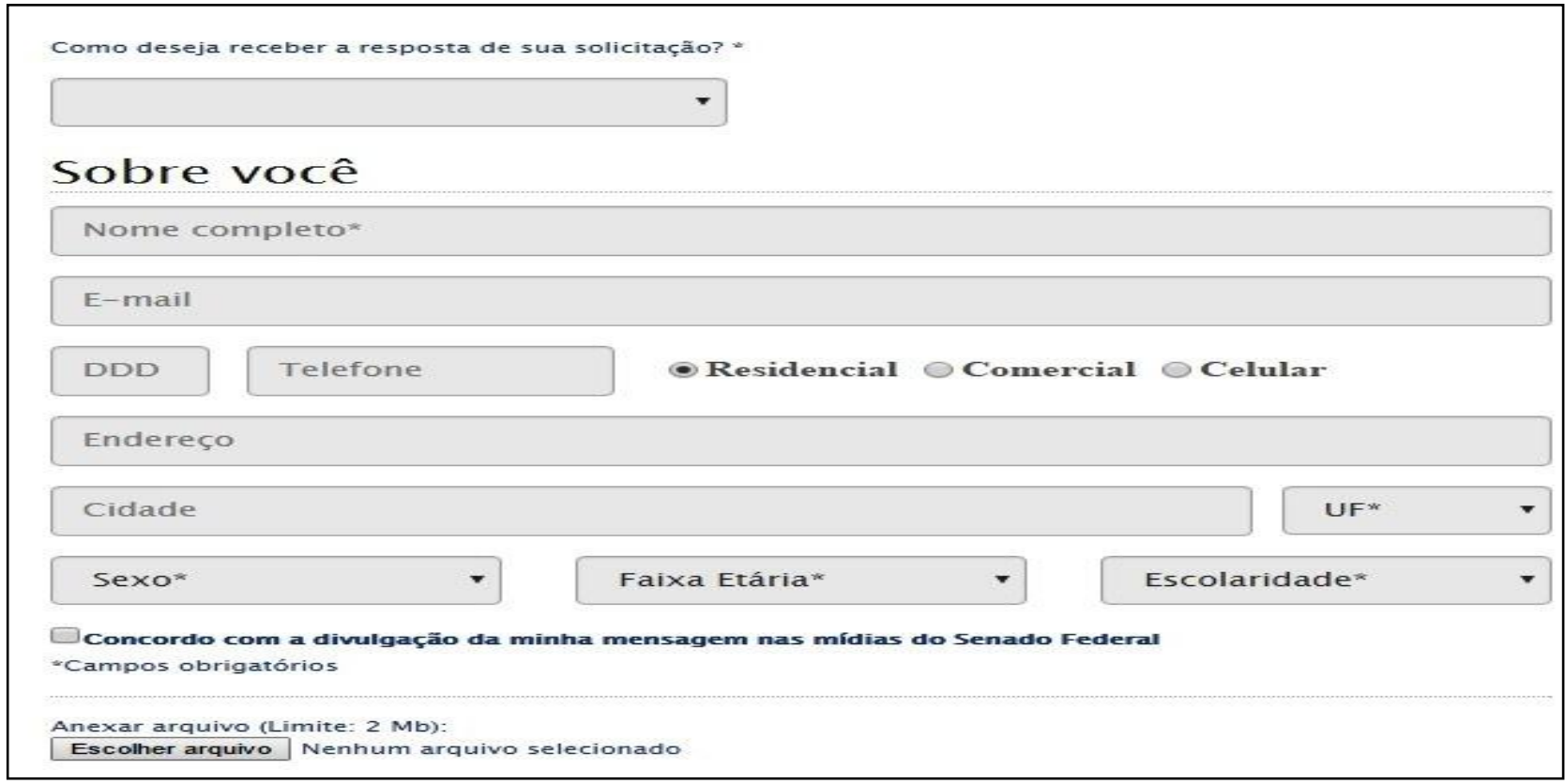

\footnotetext{
${ }^{4} \mathrm{O}$ formulário do portal do Senado Federal apresenta a seguinte mensagem: "Aqui você pode escrever sua manifestação para o Senado Federal. Esclarecemos que não respondemos questões de competência dos Poderes Executivo e Judiciário, nem às esferas estaduais e municipais; também não é nossa competência solucionar ou encaminhar pedidos de ordem pessoal; prestar assessoria jurídica; responder mensagens que contenham ameaças, insultos e expressões de baixo calão; que encaminhem reprodução de matérias e boatos, ou que sejam anônimas. São consideradas anônimas aquelas que não contêm o nome completo do cidadão" (BRASIL, 2016b).
} 
(BRASIL, 2016d)

Ainda na análise do quesito da identificação do demandante, no portal da Câmara dos Deputados é requisito obrigatório, não sendo possível o anonimato. Assim como a especificação da motivação da mensagem, que se limita às opções de: solicitação $^{5}$, Lei de Acesso à Informação (LAI) ${ }^{6}$, denúncia/reclamação ${ }^{7}$, elogio ${ }^{8}$ e manifestação/sugestão ${ }^{9}$.

Há algumas outras informações exigidas para o envio do formulário que podem inviabilizar a demanda. Além dos dados pessoais já demonstrados, destaca-se que no portal da Câmara de Deputados o e-mail e o telefone são campos obrigatórios. Salienta-se que a exigência obrigatória de algum contato que envolve o acesso ao computador ou telefone limita o acesso, pois não é possível afirmar que a totalidade da sociedade brasileira possui acesso a essas tecnologias, por mais comuns que possam parecer.

Somente o sítio da Câmara dos Deputados permite o acompanhamento da demanda por parte do solicitante, pois no envio do formulário gera um número de protocolo. A possibilidade de o cidadão poder manter-se informado acerca do andamento de seu pedido transmite a confiança de que obterá resposta, permitindo controlar os estágios de sua tramitação, o que se mostra bastante positivo.

Aliado a esses mecanismos tradicionais percebe-se a tentativa de inserir os órgãos públicos também nos sites de redes sociais, aprofundando a interação com os cidadãos, com um percentual expressivo, “já estão presentes por meio de perfil ou conta próprios nessas redes, 92\% dos órgãos federais e 74\% dos estaduais. Plataformas como Facebook ou YahooProfile (68\%) e o Twitter (50\%) foram as mais utilizadas segundo o total de órgãos públicos federais e estaduais" (BRASIL, 2016, p. 166).

Os espaços virtuais para debate público do Senado Federal são as redes sociais do Twitter, Facebook, Flickr, Instagram, Tumblr e o canal do Youtube, enquanto a Câmara dos Deputados tem perfil público somente no Twitter e no Facebook. Ressalta-se que a existência

\footnotetext{
5 A solicitação refere-se à demanda sobre serviços, produtos e programas desenvolvidos pela Câmara dos Deputados.

${ }^{6}$ A demanda sobre a LAI permite a solicitação de informação legislativa ou administrativa produzida pela Câmara dos Deputados ou sob sua guarda.

${ }^{7} \mathrm{Na}$ opção denúncia/reclamação possibilita a comunicação de indícios de ilegalidade ou abuso de poder no âmbito da atuação da Câmara de Deputados ou irregularidades ou não funcionamento de atividades, produtos, serviços da Casa.

${ }^{8}$ O elogio é para envio de feedback da satisfação com as atividades, produtos e serviços da Câmara de Deputados.

${ }^{9}$ Por fim, a manifestação/sugestão é o lugar que o cidadão pode enviar a posição pessoal quanto a fatos políticos ou legislativos, sugerir ideias ou propostas para criar ou aprimorar o processo legislativo ou serviços da Casa.
} 
de sites de redes sociais permitem ampliar a participação da população e possibilitam uma interação com o Poder Público informal com potencial de aprofundar o interesse de participação cidadã nas questões públicas.

O diferencial de cada sítio que proporciona uma construção colaborativa ${ }^{10}$ é o canal e-Cidadania do Senado Federal, que permite ao cidadão tanto propor um debate, quanto apresentar uma ideia legislativa. A proposta para discussão refere-se à audiência pública que existe para incentivar o debate entre os parlamentares e especialistas da sociedade brasileira, enquanto que a ideia legislativa ocorre uma contribuição do cidadão para a função legislativa do Senado. O e-Cidadania é um canal que permite que o cidadão opine, debata e que aconteça a interação com o Poder Legislativo, de acordo com Zambrano (2010, p. 23) "la participación permite a la población ejercer sus derechos democráticos y por lo mismo afectar la manera en que el gobierno representativo se ejerce así como la dirección que la democracia debe tomar en el país".

Na Câmara dos Deputados há o Portal e-Democracia que utiliza a internet como um instrumento para incentivar a participação da população no debate. De acordo com Cristiano Ferri Soares de Faria (2012, p. 185), o referido portal “[...] é um espaço virtual, interativo, com interface amigável, criado para estimular os cidadãos e organizações civis de todo o tipo e interesse a contribuírem na formulação de leis federais, assim como para auxiliar os deputados no trabalho de fiscalização e controle [...]". Pode-se dizer que é um canal em que os cidadãos têm espaço para discutir sobre as novas propostas de lei e contribuir para a formulação de políticas públicas de acordo com a realidade que se inserem.

O Portal e-Democracia, desenvolvido pela Câmara dos Deputados, é dividido em dois grandes espaços de participação: as Comunidades Legislativas e o Espaço Livre. No primeiro, é possível participar de debates de temas disponibilizados e relacionados a projetos de lei já existentes. Essas Comunidades oferecem diferentes instrumentos de participação e, ainda, orientações quanto ao andamento da matéria no Congresso Nacional. Já no Espaço Livre, o próprio usuário pode definir o tema da discussão.

De modo geral, apesar dos portais analisados ofertarem diversos canais de comunicação para os cidadãos, notou-se que os mecanismos de acessibilidade estão ausentes,

\footnotetext{
${ }^{10}$ Importante salientar que nos Portais de participação cidadã, na forma colaborativa, a observação restringiu-se a uma análise de que se era possível efetivar uma participação e se esses mecanismos também estavam adequados de acordo com os padrões de acessibilidade.
} 
principalmente nos portais de participação e-Cidadania e e-Democracia. Podendo ser um impeditivo de acesso da pessoa com deficiência.

Salienta-se que o portal do Congresso Nacional também foi observado, com os mesmos parâmetros apresentados, em virtude de suas funções de fiscalização e controle. Contudo, não foi possível incluir os resultados ao longo da exposição, pois o sítio é um compilado incompleto das informações dos sites do Senado Federal e da Câmara dos Deputados, sem cumprir nenhuma recomendação exarada pelo Poder Público.

Mesmo sem sua inclusão para fins de análise, a rápida verificação feita permite constatar a ausência dos mecanismos de acessibilidade. O único ponto positivo é a disponibilização do histórico dos parlamentares, em que especifica os projetos e relatórios que cada um apresentou, ferramenta que contribui para o acesso à informação, além de ser uma fonte de dados que propiciam o controle da sociedade perante os parlamentares, uma vez que detalha todas as atividades, independentemente do número de mandatos.

Quanto aos requisitos de acessibilidade percebe-se que o site da Câmara de Deputados cumpre em maior grau as recomendações de acessibilidade em comparação com o portal do Senado Federal, mas em ambos falta a oferta dos instrumentos de acessibilidade na página específica que está disponibilizada o meio de comunicação. Segundo Francisco Paulo Jamil Almeida Marques (2011, p. 104), “o Portal da Câmara dos Deputados foi criado em 1996 e já se consolidou como uma das experiências em democracia digital mais importantes do Brasil [...]". Talvez o tempo de existência do portal contribua para a maior preocupação e esforços políticos para a concretização da acessibilidade, além de ser a Casa que diretamente representa o povo.

\section{CONCLUSÃO}

A inserção do Poder Legislativo brasileiro na sociedade em rede potencializa a alteração da relação entre os representantes e representados, uma vez que propicia uma maior interação. Além dos cidadãos terem um maior acesso a informações que permitem fiscalizar, controlar e participar das decisões públicas.

Para que esses canais de comunicação ofertados sejam efetivos, não basta a simples presença deles nos portais online. É imprescindível que nas páginas em que estejam os formulários, os dados sobre e-mail, telefone, Fale Conosco ou qualquer via de contato, se 
façam presentes os mecanismos de acessibilidade, para que haja a inclusão das pessoas com deficiência nessa participação política. Porém isso não se visualizou na observação apresentada no presente artigo, uma vez que se verificou uma pluralidade de formas de comunicação do cidadão com o Poder Legislativo, porém nelas estavam ausentes os mecanismos de acessibilidade, encontrados principalmente nas páginas iniciais ou naquelas que envolvem conteúdo de notícias.

Nesse contexto, afirma-se através dos dados obtidos que a efetivação da Governança Eletrônica em âmbito do Poder Legislativo Federal brasileiro ainda tem importantes avanços para serem realizados, os quais necessitam de ações dos próprios parlamentares e cumprimento das normativas e recomendações exaradas, principalmente quanto à temática da acessibilidade. Por enquanto, os preceitos da Governança de maior participação e universalização de oportunidades são ignorados, pois a ausência de acessibilidade exclui muitos atores sociais, principalmente as pessoas com deficiência, camada da população geralmente excluída das decisões políticas.

\section{REFERÊNCIAS}

BARBOSA, Lívia; DINIZ, Debora; SANTOS, Wederson. Diversidade Corporal e perícia médica no Benefício de Prestação Continuada. In: DINIZ, Debora; MEDEIROS, Marcelo; BARBOSA, Lívia. (Org.). Deficiência e igualdade. Brasília: Letras Livres, 2010.

BERNARDES, Marciele Berger; SANTOS, Paloma Maria; ROVER, Aires José. Lei de Acesso à Informação e o debate acerca da divulgação de dados remuneratórios de servidores públicos. Revista Democracia Digital e Governo Eletrônico, nº8, p. 281-312, 2013.

BOBBIO, Norberto. Igualdade e liberdade. Trad. de Carlos Nelson Coutinho. $2^{\circ}$ ed. Rio de Janeiro: Ediouro, 1997.

BRAGA, Lamartine Vieira; ALVES, Welington Souza; FIGUEIREDO, Rejane Maria da Costa; SANTOS, Rildo Ribeiro dos. O papel do Governo Eletrônico no fortalecimento da governança do setor público. In: Revista do Serviço Público Brasília 59 (1): 05-21 Jan/Mar 2008. Disponível em:

<http://repositorio.enap.gov.br/bitstream/handle/1/1468/2008\%20Vol.59,n.1\%20Lamartine.p df? sequence=1\&isAllowed=y> . Acesso em: 21 abr. 2017.

BRASIL. Comitê Gestor da Internet no Brasil (CGI.br). Pesquisa sobre o uso das tecnologias da informação e comunicação no setor público brasileiro [livro eletrônico]: TIC Governo Eletrônico 2015 = Survey on the use of information and communication technologies in the Brazilian public sector : ICT Electronic Government 2015 / [coordenação executiva e editorial / executive and editorial coordination Alexandre F. Barbosa ; tradução 
para o inglês / translation into english Prioridade Consultoria]. - - São Paulo: Comitê Gestor da Internet no Brasil, 2016. Disponível em: <

http://www.cgi.br/media/docs/publicacoes/2/TIC_eGOV_2015_LIVRO_ELETRONICO.pdf> . Acesso em: 21 abr. 2016.

Constituição da República Federativa do Brasil de 1988. Disponível em: < http://www.planalto.gov.br/ccivil_03/constituicao/ConstituicaoCompilado.htm >. Acesso em: 16 abr. 2016.

.Decreto $n^{0} 3.298$, de 20 de dezembro de 1999. Regulamenta a Lei $\mathrm{n}^{-} 7.853$, de 24 de outubro de 1989, dispõe sobre a Política Nacional para a Integração da Pessoa Portadora de Deficiência, consolida as normas de proteção, e dá outras providências. Brasília, 20 de dezembro de 1999. Disponível em: < http://www.planalto.gov.br/ccivil_03/decreto/d3298.htm >. Acesso em: 28 fev. 2016.

Decreto no 5.134, de 7 de julho de 2004. Aprova a Estrutura Regimental e o Quadro Demonstrativo dos Cargos em Comissão e das Funções Gratificadas do Ministério do Planejamento, Orçamento e Gestão, e dá outras providências. Brasília, 7 de julho de 2004b. Disponível em: <http://www.planalto.gov.br/ccivil_03/_ato20042006/2004/decreto/d5134.htm>. Acesso em: 28 fev. 2016.

- Instituto Brasileiro de Geografia e Estatística. Censo Demográfico 2010: Características gerais da população, religião e pessoas com deficiência. Rio de Janeiro, p.1215, 2010b. Disponível em: <http://biblioteca.ibge.gov.br/visualizacao/periodicos/94/cd_2010_religiao_deficiencia.pdf>. Acesso em: 28 fev. 2016.

Lei $\mathbf{n}^{\circ}$ 12.527, de 18 de novembro de 2011. Regula o acesso a informações previsto no inciso XXXIII do art. $5^{-}$, no inciso II do $\S 3^{\circ}$ do art. 37 e no $\S 2^{\circ}$ do art. 216 da Constituição Federal; altera a Lei no 8.112 , de 11 de dezembro de 1990; revoga a Lei $\mathrm{n}^{\mathrm{o}} 11.111$, de 5 de maio de 2005, e dispositivos da Lei $\mathrm{n}^{\mathrm{o}} 8.159$, de 8 de janeiro de 1991; e dá outras providências. Disponível em: < http://www.planalto.gov.br/ccivil_03/_ato20112014/2011/lei/112527.htm>. Acesso em: 28 fev. 2016.

Lei $n^{0}$ 13.146, de 6 de julho de 2015.

Institui a Lei Brasileira de Inclusão da Pessoa com Deficiência (Estatuto da Pessoa com Deficiência). Brasília, 6 de julho de 2015. Disponível em: < http://www.planalto.gov.br/ccivil_03/_Ato2015-2018/2015/Lei/L13146.htm>. Acesso em: 28 fev. 2016.

Portal Câmara de Deputados. Disponível em: < http://www2.camara.leg.br/ > . Acesso em: 28 fev. 2016 .

Portal Congresso Nacional. Disponível em: <

http://www.congressonacional.leg.br/portal/>. Acesso em: 28 fev. 2016c.

Portal Senado Federal. Disponível em: < http://www12.senado.leg.br/hpsenado>. Acesso em: 28 fev. 2016b. 
BRAVO, Álvaro Sánchez. A nova sociedade tecnológica: da inclusão ao controle social: a Europ@ é exemplo?. Tradução Clovis Gorczevski. Santa Cruz do Sul: EDUNISC, 2010.

CANOTILHO, J.J. Gomes. Direito constitucional e teoria da constituição. $7^{\mathrm{a}}$ ed. Coimbra: Almedina, 2003.

CARDOSO, Gustavo. A mídia na sociedade em rede: filtros, vitrines, notícias. Rio de Janeiro: FGV, 2007.

CARVACHO T, Pablo. Participación (digital) para el monitoreo de la política. In: LE MONDE DIPLOMATIQUE. Democracia eletrectrónica: ¿Qué desafíos para América Latina? Santiago do Chile: 2010.

CASTELLS, Manuel. A Sociedade em Rede: a era da informação: economia, sociedade e cultura; v. 1. Trad. Roneide Venancio Majer. 6ª ed. São Paulo: Paz e Terra, 2011.

DIÉGUEZ, Gonzalo; RÍOS, Maximiliano Campos. ¿Hacia uma nueva configuración de las relaciones entre el gobierno y la cidadanía? Breves apuntes sobre el gobierno eletrônico. In: ELIZALDE, Luciano; RIORDA, Mario. Comunicación Gubernamental 360. Ciudad Autónoma de Buenos Aires: La Crujía, 2013, p. 241-250.

DINIZ, Débora; BARBOSA, Lívia; SANTOS, Wederson Rufino dos. Deficiência, direitos humanos e justiça. São Paulo, Sur - Revista Internacional de Direitos Humanos, n. 11, p. 65-78, 2010. Disponível em:

$<$ http://repositorio.unb.br/bitstream/10482/8216/1/ARTIGO_DeficienciaDireitosHumanos.pdf $>$. Acesso em: 14 ago. 2015.

DUFLOTH, Simone Cristina; FREITAS, Diego Roger Ramos; ROCHA, Elisa Maria Pinto da. Portais de Governo dos Estados brasileiros: serviços e informações a um clique. In:

BRASIL. Comitê Gestor da Internet no Brasil (CGI.br). Pesquisa sobre o uso das tecnologias da informação e comunicação no setor público brasileiro [livro eletrônico]: TIC Governo Eletrônico 2013 = Survey on the use of information and communication technologies in the Brazilian public sector : ICT Electronic Government 2013 / [coordenação executiva e editorial / executive and editorial coordination Alexandre F. Barbosa ; tradução para o inglês / translation into english Prioridade Consultoria]. - - São Paulo : Comitê Gestor da Internet no Brasil, 2014. Disponível em:

<http://www.cgi.br/media/docs/publicacoes/2/TIC_eGOV_2013_LIVRO_ELETRONICO.pdf >. Acesso em: 15 dez. 2015.

FARIA, Cristiano Ferri Soares de Faria. O parlamento aberto na era da internet. Pode o povo colaborar com o Legislativo na elaboração das leis? Brasília: Câmara de Deputados, 2012.

GALINDO AYUDA, Fernando. Democracia, internet y gobernanza: una concreción.

Sequência (Florianópolis), Florianópolis, n. 65, dez. 2012 . Disponível em:

<http://www.scielo.br/scielo.php?script=sci_arttext\&pid=S2177-

$70552012000200003 \& \operatorname{lng}=$ pt\&nrm=iso>. Acesso em: 26 maio 2014. 
GOMES, Wilson. Participação política online: Questões e hipóteses de trabalho. In: MAIA, Rousiley Celi Moreira; GOMES, Wilson; MARQUES, Francisco Paulo Jamil Almeida (Orgs.). Internet e participação política no Brasil. Porto Alegre: Sulina, 2011.

HAZARD, Damian; GALVÃO FILHO, Teófilo Alves; REZENDE, André Luiz Andrade. Inclusão digital e social de pessoas com deficiência: textos de referência para monitores de telecentros. - Brasília: UNESCO, 2007.

JARDIM, José Maria. A construção do e-gov no Brasil: configurações políticoinformacionais. In: ENCONTRO NACIONAL DA CIÊNCIA DA INFORMAÇÃO. Anais. Salvador: CINFORM, 2004. Disponível em:

<http://www.egov.ufsc.br/portal/sites/default/files/anexos/30772-32926-1-PB.pdf> . Acesso em: 20 abr. 2017.

LEAL, Rogério Gesta. Estado, administração pública e sociedade: novos paradigmas. Porto Alegre: Livraria do Advogado, 2006.

MARQUES, Francisco Paulo Jamil Almeida. Participação, instituições políticas e internet: Um exame dos canais participativos presentes nos portais da Câmara e da Presidência do Brasil. In: MAIA, Rousiley Celi Moreira; GOMES, Wilson; MARQUES, Francisco Paulo Jamil Almeida (Orgs.). Internet e participação política no Brasil. Porto Alegre: Sulina, 2011.

MARTÍNEZ, José María Seco; PRIETO, Rafael Rodrpiguez. Espacios y ritmos para una nueva concepción de la ciudadanía. In:JULIOS-CAMPUZANO, Alfonso de (Ed.). Ciudadanía y derecho en la era de la globalización. Madrid: Dykinson, 2007.

ORGANIZAÇÃO DAS NAÇÕES UNIDAS. Convenção sobre direitos das pessoas com deficiência. [2006]. Disponível em: < http://www.acessibilidade.net/convencao.php>. Acesso em: 16 abr. 2017.

Department of Economic and Social Affairs. United Nations E-

Government Survey 2014: E-Governement for the future we want. New York: United Nations, 2014. Disponível em: < http://unpan3.un.org/egovkb/en-us/Reports/UN-EGovernment-Survey-2014>. Acesso em: 16 nov. 2014.

Department of Economic and Social Affairs. United Nations E-

Government Survey 2016: E-Government in Support of Sustainable Development. New York: United Nations, 2016. Disponível em: < http://workspace.unpan.org/sites/Internet/Documents/UNPAN96407.pdf>. Acesso em: 02 mai. 2017.

Department of Economic and Social Affairs, Division for Public Administration and Development Management. World Public Sector Report 2003: EgovernmentattheCrossroads. Nova York: United Nations, 2003. Disponível em:<https://publicadministration.un.org/publications/content/PDFs/E- 
Library\%20Archives/World\%20Public\%20Sector\%20Report\%20series/World\%20Public\%20 Sector\%20Report.2003.pdf>, Acesso em: 16 nov. 2014.

PÉREZ LUÑO, Antonio-Enrique. Dimensiones de la igualdade. Cuadernos "Bartolomé de

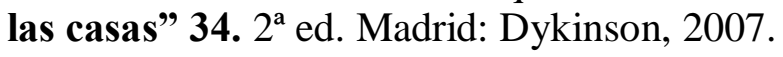

SIAU, Keng; LONG, Yuan. "Synthesizing e-government stage models - a meta-synthesis based on meta-ethnography approach". In Industrial Management \& Data Systems 105[4], pp. 443-458.2005. Disponível em: <http://www.irma-international.org/viewtitle/32506/>. Acesso em: 12 jan. 2016.

ZAMBRANO, Raúl. Tecnologías de información y comunicación (TICs), democracia y participación. In: LE MONDE DIPLOMATIQUE. Democracia eletrectrónica: ¿Qué desafíos para América Latina? Santiago do Chile: 2010. 